\title{
EDUCAÇÃO A DISTÂNCIA E OLIMPÍADA NACIONAL DE HISTÓRIA DO BRASIL: O ÊXITO DA MODALIDADE EM UM PROGRAMA INOVADOR
}

\author{
Silvia Eliane de Oliveira Basso ${ }^{1}$, Maria Luisa Furlan Costa $^{2}$, Patrícia L.L. Mertzig Gonçalves de Oliveira ${ }^{3}$ \\ ${ }^{1}$ Instituto Federal do Paraná, Campus Umuarama,PR. ${ }^{2}$ Universidade Estadual de Maringá, UEM, PR. Professora do \\ Departamento de Fundamentos da Educação, Coordenadora do Núcleo de Educação a Distância - UEM. ${ }^{3}$ Universidade \\ do Oeste Paulista, Faculdade de Arte, Ciências, Letras e Educação de Presidente Prudente, Presidente Prudente, SP. E- \\ mail: silvia.basso@ifpr.edu.br
}

\section{RESUMO}

As ferramentas da educação a distância vêm sendo utilizadas em inúmeras experiências de ensino, pesquisa e extensão, corroborando a qualidade de ensino que se pode atingir com essa modalidade. Este estudo tem como objetivo analisar a Olimpíada Nacional de História do Brasil (ONHB), programa de extensão mantido pela Universidade Estadual de Campinas, como experiência exitosa no uso de tecnologias educacionais para promover inovação no ensino e possibilidade de pesquisa. A metodologia adotada é o estudo de caso, de abordagem qualitativa, numa perspectiva historicista. Concluímos que o programa ONHB alcançou a milhares de estudantes por todo o país, incentivando o estudo e a pesquisa em história, porque valeu-se das possibilidades das tecnologias de informação e comunicação, tornando-as meios de aprendizagem eficientes.

Palavras-chave: Educação a Distância, Olimpíada de História, Tecnologias educacionais.

\section{DISTANCE EDUCATION AND NATIONAL HISTORY OLIMPIC OF BRAZIL: THE SUCCESS OF THE MODALITY IN AN INNOVATIVE PROGRAM}

\begin{abstract}
The tools of distance education have been used in numerous teaching, research and extension experiences, corroborating with the quality of teaching that can be achieved with this modality. This study aims to analyze the National History Olimpic of Brazil (NHOB), an extension program maintained at the State University of Campinas, as a successful experiment in use of educational technologies to promote innovation in teaching and the possibility of research. The methodology adopted is a case study, with a qualitative approach, in a historicist perspective. We conclude that the NHOB program has reached thousands of students across the country, encouraging study and research in history, because it increases the possibilities of information and communication technologies, making them efficient means of knowledge.
\end{abstract}

Keywords: Distance Education, History Olympiad, Educational Technologies.

\section{INTRODUÇÃO}

Unicamp recebe alunos e professores de todo o país para a grande final da ONHB..., assim inicia-se a reportagem da página Olimpíada Nacional em História do Brasil, uma competição, que não tem as características do que tradicionalmente entendemos como competição, e que reúne estudantes dos últimos anos do ensino fundamental e médio e professores.

Especialmente comemorada, por ser essa a 10a edição da Olimpíada, esta tem proporcionado aos participantes, estudantes e professores, o contato direto com a pesquisa em história e o incentivo à novas práticas no ensino desta área do conhecimento. Particularmente, esta edição só se realizou com sucesso, alcançando milhares de estudantes, por contar com as tecnologias digitais da comunicação e informação (TIDC).

Nesse sentido, no presente artigo objetiva-se demonstrar que as ferramentas da Educação a Distância (EaD), estão cada vez mais 
presentes nos processos educacionais, sejam eles, no ensino, na pesquisa ou na extensão. No caso em análise, o tripé está contemplado no evento Olimpíada Nacional de História do Brasil (ONHB), que incentiva práticas de ensino, ocorre por meio de projeto de extensão universitária e recolhe dados para a pesquisa sobre ensino de história em todo o país, num só momento.

\section{METODOLOGIA}

As tecnologias digitais de informação e comunicação (TDIC) são resultado do desenvolvimento histórico e inserem-se no contexto social. Assim sendo, o método de estudo é o historicismo, que, por meio do concreto caracterizado em documentos e publicações, procura recriar o caminho percorrido como forma de compreender o fenômeno ou fato. Para as análises realizadas, utilizou-se também a abordagem qualitativa e a metodologia de estudo de caso.

Com respeito ao seu objetivo, essa pesquisa se caracteriza como explicativa por, "identificar os fatos que subjazem à ocorrência de determinados fenômenos" (MARCONI; LAKATOS, 2017, p.298). Segundo Minayo (1993, p.21-22 apud MARCONI; LAKATOS, 2017, p. 303), a abordagem qualitativa explora um universo de significados, motivos, aspirações e atitudes que vão além de operacionalização de variáveis, identificando-se tradicionalmente com o estudo de caso, que aqui tem como objetivo "apreender determinada situação e descrever a complexidade do fato", com ênfase na interpretação de contexto.

Nesta perspectiva de pesquisa, as informações foram coletadas na página virtual do evento ONHB na internet entre outros meios eletrônicos de divulgação e informação sobre a olimpíada e analisados a partir de referencial teórico da educação a distância.

\section{RESULTADOS}

A ONHB surgiu em 2009 pela iniciativa da Professora Cristina Meneguello do Departamento de História da Universidade Estadual de Campinas (Unicamp), e é atualmente coordenada por ela e pela Professora Alessandra Pedro. A proposta, de acordo com Meneguello, mentora do projeto, surgiu a partir da proposição do Museu Exploratório de Ciência da Universidade de Campinas (Unicamp), que tem como papel "estimular a curiosidade científica, disseminando o conhecimento científico e tecnológico de forma crítica" (MC/UNICAMP), e de trazer também as ciências humanas para o palco da disseminação da cultura científica (MUSEU EXPLORATÓRIO DE CIÊNCIAS, 2018).

A ideia inicial era realizar uma gincana pela internet e transformou-se num evento que atingiu 16.000 estudantes em 2009 e chegou ao número de 57.500 estudantes em 14.384 equipes em 2018. Não só os números são impressionantes mas também a metodologia de ação e os materiais de estudo colocados à disposição de professores e estudantes durante todo o processo.

De acordo com Meneguello (2011), a implementação da Olimpíada exigiu a formação de uma equipe de pesquisadores do Programa de Pós-Graduação da Unicamp para sustentação teórico-metodológica e a criação de uma plataforma e sistema interativo, por meio do qual os estudantes participantes passam a ter acesso a um acervo digitalizado de documentos históricos. Dessa forma, foi cumprido um dos objetivos do programa ONHB que é proporcionar o ensino de história por meio dos fundamentos do trabalho do historiador, qual sejam leitura e análise de documentos como mapas, gravuras, textos jornalísticos, documentos oficiais e mídias em geral.

Nas primeiras edições ocorriam cinco fases on-line e a última etapa presencial na própria Unicamp. Na última edição, encerrada em agosto de 2018, foram seis fases on-line, ao longo das quais as equipes formadas por três membros podendo ser de turmas e séries distintas, a partir do 8o ano do ensino fundamental até o fim do ensino médio, com a orientação de um professor de história da escola, recebiam no início da semana, atividades para resolver no ambiente da equipe na plataforma, tendo seis dias para as respostas finais, cumprindo outro objetivo do programa: o trabalho em equipe

Sendo incentivados a encontros semanais para debate e pesquisa sobre as dúvidas, tanto as equipes quanto o professor, podiam acompanhar as respostas em rascunhos até decidirem-se pela resposta final. O uso de ferramentas de comunicação na web, como skype, WhatsApp, discord e outras, também podiam ser utilizados para troca de impressões ou dúvidas.

A internet traz uma
linguagem viva e ágil e
possibilita virtualmente
que se atinjam os


interessados em todo o território nacional, seja nas escolas ou nas casas, ou mesmo em lan houses (de onde muitos enviaram as suas respostas). A internet traz interação e utilização contínua, pois mesmo depois de terminada a Olimpíada qualquer um pode acessar as perguntas ou o banco de dados de documentos. Assim a plataforma da Olimpíada multiplicadora de leituras e estudos em História do Brasil. (MENEGUELLO, 2010).

Na plataforma do evento os participantes podiam acessar os textos base e indicações de leitura. Encontrava-se à disposição, cerca de dez questões com quatro alternativas possíveis, além de uma tarefa com diferentes graus de dificuldades e os quesitos para a correção e classificação. Estava disponível também um acervo para outras experiências (bagagens) e estudos, fazendo da ONHB, uma experiência inovadora no ensino de história, não só pela abordagem metodológica do ensino como pela organização e possibilidade de participação por meio das tecnologias.

\section{DISCUSSÃO}

$A$ EaD é modalidade educacional que vem sendo desenvolvida desde o início do século $X X$ quando a extensão das ferramentas de comunicação, como a correspondência e o rádio, vulgarizaram-se, alcançando pessoas nos mais diversos lugares. A era das tecnologias da informação e comunicação tornara-se realidade.

Embora reconhecida como técnica didático-pedagógica desde a década de 1970 no Brasil, a tecnologia era, segundo Arnaldo Niskier (1993), vista e usada como forma suplementar de educação aos grupos historicamente excluídos dos processos formais de ensino.

Afirmada como modalidade educacional, no contexto da nova Lei de Diretrizes e Bases da Educação - LDB (Lei № 9.394/96), a EaD é instituída no contexto da defasagem de vagas no Ensino Superior (BRASIL, 1996). Já explorada pela iniciativa privada, a modalidade é assumida então como política pública no Sistema Universidade
Aberta do Brasil - UAB (Decreto № 5.800/06) (BRASIL, 2006).

Destarte, as ferramentas da EaD têm sido propiciadoras de uma gama imensa de oportunidades no ensino, na pesquisa e na extensão, como já se destacou em outra oportunidade, ao tratar das possibilidades ampliadas da extensão por meio da educação a distância (BASSO; COSTA, 2018).

Como resultado do contexto de massificação de aparelhos tecnológicos que utilizam a internet, as chamadas TDIC, criou-se uma nova realidade num curto espaço de tempo, como nos aponta Niskier:

De uma civilização verbal, passou-se a outra, visual e auditiva. A imprensa, o jornal, o anúncio publicitário, a fotografia, o cinema, o rádio, a televisão e o computador vem modificando o homem e o próprio meio cultural. Essa apropriação dos meios de comunicação permitiu ao homem dominar o espaço e o tempo. Surge uma cultura de massa em que todos recebemos os mesmos estímulos e os mesmos produtos (NISKIER, 1993, p. 25).

Se isso é certo na sociedade de forma geral, e a escola está inserida na sociedade, como seu resultado e decisão, a tecnologia também lhe afeta, mas precisa ser pensada em seus propósitos e não reproduzir-se apenas. Assim, tecnologia educacional "é toda e qualquer aplicação ou utilização de conhecimentos científicos, ou de outra natureza, a situações ou problemas educacionais (NISKIER, 1993, p, 26)".

Conceituando tecnologia à luz da educação, Mill (2018) apresenta concepção que atende aos propósitos dessa discussão, no Dicionário Crítico de Educação e Tecnologias e de Educação a Distância, dizendo:

A tecnologia [...] emerge
como disposição ou
habilidade de produzir
algo "racionalmente". Mas
não se limita a essa
disposição, pois ao
produzir, dando forma
(informando) à matéria, à

A tecnologia [...] emerge como disposição ou habilidade de produzir algo "racionalmente". Mas não se limita a essa produzir, dando forma (informando) à matéria, à 
energia ou mesmo ao dado, conforme os meios, o método, a intenção e o uso disponíveis e desejados, ela inaugura toda uma sorte de fenômenos que ainda escampam à nossa compreensão (MILL, 2018, p.597-598).

É a partir do contexto da presença dos meios tecnológicos e de seu uso como instrumento educativo, desdobrando-se em "fenômenos que escampam à nossa compreensão" que lança-se olhar investigativo sobre a ONHB, como programa extensionista, repercutindo no ensino e provocando a pesquisa, com possibilidade de alcançar milhares de estudantes de ensino fundamental e médio em todas as regiões do Brasil simultaneamente. Isso ocorre somente porque esses meios existem e foram utilizados de forma programada, metódica e didática, alcançado resultados que, mesmo antes da discussão como eficiência pedagógica, já alcançam o objetivo precípuo de incentivar o estudo da história, bem como o debate e a pesquisa.

A discussão e sua luta por fazer-se reconhecer como modalidade educativa tão importante e eficiente como a modalidade presencial, desvinculando a EaD do simples auxílio paliativo aos grupos socialmente excluídos, ainda é trabalho que exige intensidade de pesquisadores ${ }^{1}$, professores e demais profissionais tanto quanto é campo de disputa política e, como, não poderia deixar de ser num mundo guiado pelo capitalismo, nicho de mercado, assim como o ensino presencial.

Asseverando a substancialidade desse debate, destaca-se, nessa pesquisa, a constatação inegável da presença das TDIC como eficientes e indispensáveis recursos para a educação, demonstradas por meio de experiências exitosas como a ONHB, que chega em sua 10 a edição ampliando a cada ano o número de participantes, exatamente por conta da possibilidade de, à distância, atingir um maior número de estudantes.

\footnotetext{
${ }^{1}$ Discussão a que se dedicam grupos de pesquisa como o GPEaDTEC - Grupo de Pesquisa em Educação a Distância e Tecnologias Educacionais, da Universidade Estadual de Maringá.
}

A formatação do programa permitindo a estudantes e professores interagirem e pesquisarem juntos, discutindo temas e questões que vão para além da programação de conteúdos escolares, faz desse programa um modelo inovador para o ensino de história e um incentivador à essa área de conhecimento, por vezes relegada à condição de "matéria decorativa".

Ao alcançar os jovens por meio da linguagem e aparato midiático, a $\mathrm{EaD}$ e o programa vencem barreiras espaciais, temporais e ideológicas, aproximando o estudante de um universo acadêmico e quebrando paradigmas em relação ao estudo de história.

o regulamento da Olimpíada, ao classificar da primeira para segunda fase o maior número possível de estudantes, reabre a discussão sobre qual o papel desses programas, como, por exemplo, de incentivar os estudos desmistificando as áreas de conhecimento como acessíveis apenas a superdotados.

Outros paradigmas podem ainda ser rompidos, como o senso comum de que a juventude não se interessa por ciência e que os celulares e computadores são instrumentos de redução das relações e da comunicação e ainda o uso de um aplicativo como o discord, projetado para comunidades de jogos, tornando-o ferramenta de comunicação para a aprendizagem.

\section{CONCLUSÃO}

No início do século XIX grupos de operários ingleses, seguindo o exemplo de um operário chamado Ned Ludd, passaram a quebrar as máquinas nas fábricas, como expressão de seu estado de exploração, miséria e desemprego. Obviamente as máquinas não eram o problema, mas simbolizavam a potencialização da exploração humana.

Elas continuaram a existir, foram aperfeiçoadas, inovadas e atingem hoje todos os lugares da atuação humana, pois mesmo aqueles que ainda não se apropriam do seu uso, fazem parte de uma estatística e mapeamento, cada vez mais preciso com o uso de satélites, programas e aplicativos, que os localizam e registram.

Da mesma forma que quebrar as máquinas não resolveria o problema da exploração que já existia e também foi terrivelmente aperfeiçoada, o uso dos mais modernos artefatos de informação e comunicação, se facilitam plágios e permitem 
falsas informações, não podem por elas responsabilizar-se, pois são os mesmos a permitirem que estudantes de escolas públicas, das mais diversas regiões do país, com deficiências tecnológicas que vão do muito pouco acesso à internet a computadores desatualizados, usarem a fagulha desse manancial que ainda não Ihes foi democratizado para participarem da ONHB.

O acesso ao programa por meio das ferramentas tecnológicas ampliou significativamente a participação de mais estudantes, iniciantes da pesquisa e cidadãos aproximando-os da formação do sujeito integral como tem sido proposta nos documentos reformadores da educação. Porém, tem poucas chances de se concretizar sem avanço nas discussões sobre a educação a distância, o uso e a garantia das tecnologias educacionais, enfim da educação de qualidade.

\section{REFERÊNCIAS}

BASSO, S.E.O; COSTA, M.L.F. Ampliando as possibilidades da política de extensão na educação profissional por meio da educação a distância. Revista Brasileira da Educação Profissional e Tecnológica. [S.I.], v. 1, n. 14, p. e6873, jun. 2018. ISSN 2447-1801. Disponível em: <http://www2.ifrn.edu.br/ojs/index.php/RBEPT/ article/view/6873>. Acesso em: 16 ago. 2018. https://doi.org/10.15628/rbept.2018.6873

BRASIL. Decreto no 5.800, de 8 de Junho de 2006. Dispõe sobre o Sistema Universidade Aberta do Brasil. Diário Oficial da União, Brasília, DF, 9 jun. 2006. Disponível em: <http://www.planalto.gov.br/ccivil_03/_ato20042006/2006/decreto/d5800.htm>. Acesso em: 06 nov. 2017.

BRASIL. Lei no 9.394, de 20 de dezembro de 1996. Estabelece as diretrizes e bases da educação nacional. Diário Oficial da União, Brasília, DF, 23 dez. $1996 . \quad$ Disponível em: <http://www.planalto.gov.br/ccivil_03/leis/L9394 .htm>. Acesso em: 06 nov. 2017.

LAKATOS; E. M.; MARCONI, M.A. Metodologia científica. 7.ed. São Paulo: Atlas, 2017.

MENEGUELLO, C. Olimpíada nacional em história do Brasil - uma aventura intelectual? História Hoje. Revista Eletrônica de História. v.5, n.14, 2011. ISSN 1806-3993. Disponível em:
<http://www.anpuh.org/revistahistoria/view?ID_ REVISTA_HISTORIA=14\&impressao $>$.Acesso em: 10 ago. 2018 .

Olimpíada Nacional em História do Brasil. Entrevista com Cristina,. Meneguello. (UNICAMP), 16/02/2010. Café com História. Disponível em: $<$ https://www.cafehistoria.com.br/olimpiadanacional-em-historia-do-brasil/>. Acesso em: 10 ago. 2018.

MILL, D. (org.). Dicionário crítico de educação e tecnologias e de educação a distância. Campinas, SP: Papirus, 2018.

MUSEU EXPLORATÓRIO DE CIÊNCIAS. Unicamp, 2018. Disponível em: <http://www.mc.unicamp.br/>. Acesso em: 08 ago.2018.

NISKIER, A. Tecnologia Educacional: uma visão política. Petrópolis, RJ: Vozes, 1993.

UNIVERSIDADE ESTADUAL DE CAMPINAS. Departamento de História. Olimpíada nacional de história do Brasil 10a ONHB. Campinas: Unicamp, 2018. Disponível em: $<$ https://www.olimpiadadehistoria.com.br/pagin as/onhb10/home>. Acesso em: 08 ago. 2018.

Recebido para publicação em 17/08/2018

Revisado em 27/08/2018

Aceito em 03/09/2018 